\title{
Delineation of individual human chromosomes in metaphase and interphase cells by in situ suppression hybridization using recombinant DNA libraries
}

\author{
P.Lichter ${ }^{1}$, T. Cremer ${ }^{2 *}$, J.Borden ${ }^{2}$, L.Manuelidis ${ }^{2}$, and D.C. Ward ${ }^{1}$ \\ ${ }^{1}$ Department of Human Genetics and ${ }^{2}$ Section of Neuropathology, Yale University School of Medicine, New Haven, CT 06510, USA
}

\begin{abstract}
Summary. A method of in situ hybridization for visualizing individual human chromosomes from pter to qter, both in metaphase spreads and interphase nuclei, is reported. DNA inserts from a single chromosomal library are labeled with biotin and partially preannealed with a titrated amount of total human genomic DNA prior to hybridization with cellular or chromosomal preparations. The cross-hybridization of repetitive sequences to nontargeted chromosomes can be markedly suppressed under appropriate preannealing conditions. The remaining single-stranded DNA is hybridized to specimens of interest and detected with fluorescent or enzymelabeled avidin conjugates following post-hybridization washes. DNA inserts from recombinant libraries for chromosomes 1 , $4,7,8,13,14,18,20,21,22$, and $\mathrm{X}$ were assessed for their ability to decorate specifically their cognate chromosome; most libraries proved to be highly specific. Quantitative densitometric analyses indicated that the ratio of specific to nonspecific hybridization signal under optimal preannealing conditions was at least $8: 1$. Interphase nuclei showed a cohesive territorial organization of chromosomal domains, and laserscanning confocal fluorescence microscopy was used to aid the 3-D visualization of these domains. This method should be useful for both karyotypic studies and for the analysis of chromosome topography in interphase cells.
\end{abstract}

\section{Introduction}

Chromosome banding techniques have facilitated the identification of specific human chromosomes and presently provide the major basis upon which chromosomal aberrations are diagnosed. The interpretation of chromosome banding patterns requires skilled personnel and is often technically difficult, especially with respect to detecting minor structural changes and when analyzing complex karyotypes, such as those of highly aneuploid tumor cells (see Cremer et al. 1988 b). An additional complexity is that readable metaphase chromosome spreads are sometimes very difficult or impossible to prepare from certain cell types or tissues. Alternative methods for identifying chromosomal aberrations could aug-

\footnotetext{
* Present address: Institut für Humangenetik und Anthropologie der Universität, Im Neuenheimer Feld 328, D-6900 Heidelberg 1, Federal Republic of Germany

Offprint requests to: $\mathrm{P}$. Lichter
}

ment current methods of cytogenetic analysis, particularly if applicable to both mitotic and interphase cell populations.

Over the past few years a considerable body of evidence has been obtained which indicates that the DNA of individual chromosomes occupies focal territories, or spatially cohesive domains, within mammalian interphase nuclei (Cremer et al. 1982; Hens et al. 1983; Schardin et al. 1985; Manuelidis 1985a; Pinkel et al. 1986a). These observations strongly suggest that chromosome-specific probe sets could be used to detect numerical or structural aberrations of chromosomal domains in non-mitotic cells, an approach termed "interphase cytogenetics" (Cremer et al. 1986). Indeed, recent in situ hybridization studies have demonstrated the prenatal diagnosis of trisomy-18 with interphase cells (Cremer et al. 1986) and the detection of numerical chromosomal abnormalities in tumor cell lines (Cremer et al. 1988a) using chromosomespecific repetitive DNAs as probes. Since all chromosomespecific repetitive DNAs reported to date are localized to discrete subregions of each chromosome, this class of DNA probes would be unsuitable for analyses of many types of chromosomal aberrations, e.g., translocations and deletions. However, the ability to detect uniquely the entire spectrum of sequences comprising a specific chromosome would make such analyses possible. Furthermore, such a general labeling technique would allow one to address fundamental questions concerning the spatial organization of chromosomal DNA within interphase nuclei.

In this report we present a hybridization strategy suitable for the specific cyto-staining of individual human chromosomes using commercially available genomic DNA libraries that originated from flow-cytometry sorted human chromosomes (Van Dilla et al. 1986). Suppression of hybridization signals from ubiquitous repeated sequences, such as the $A l u$ and $K p n I$ elements, was achieved using total human DNA in a reannealing procedure that is based on rapid reassociation kinetics. Similar principles were used previously to facilitate the selective hybridization of unique sequence subsets from cosmid DNA clones for Southern blotting (Sealey et al. 1985) and in situ hybridization experiments (Landegent et al. 1987). We demonstrate here the specific labeling of individual chromosomes in both metaphase spreads and interphase nuclei, as well as the feasibility of using computer-assisted optical sectioning for 3-D reconstruction of chromosomal domains for the analysis of nuclear topography. In an accompanying paper (Cremer et al. 1988b) we further document the utility of this 
technique to detect chromosomal aberrations in highly aneuploid tumor cells.

\section{Materials and methods}

\section{DNA libraries}

The following human chromosome genomic libraries were obtained from the American type culture collection: LA01NS01 (chromosome 1), LL04NS01 (chromosome 4), LA07NS01 (chromosome 7), LL08NS02 (chromosome 8), LA13NS03 (chromosome 13), LL14NS01 (chromosome 14), LL18NS01 (chromosome 18), LL20NS01 (chromosome 20), LL21NS02 (chromosome 21), LA22NS03 (chromosome 22), LA0XNL01 (chromosome $\mathrm{X}$ ). Amplification of these phage libraries on agar plates (using LE 392 cells as the bacterial host), purification of the $\lambda$ phages and extraction of phage-DNA pools were carried out according to standard protocols (Maniatis et al. 1982).

\section{Preparation of metaphase spreads and fibroblast cells}

Phytohemagglutinin-stimulated lymphocytes from a normal adult male (46, XY) were cultured in McCoy's 5A medium (GIBCO), arrested with Colcemid, treated with a hypotonic solution of $0.075 \mathrm{MKCl}$, fixed in acetic acid-methanol and metaphase spreads made by standard procedures. Low-passage normal human foreskin fibroblasts $(46, \mathrm{XY})$ were grown on microscope slides, fixed with paraformaldehyde, and permeabilized as described (Manuelidis 1985b), for study of preparations with a more intact three-dimensional structure.

\section{Preparation of DNAs for in situ hybridization}

Insert DNA probes. Genomic DNA fragments from the chromosomal DNA libraries were separated as a pool from the Charon $21 \mathrm{~A}$ vector arms by digestion with the appropriate restriction enzyme [Eco RI (LA libraries) or HindIII (LL libraries)] followed by preparative electrophoresis in $0.6 \%$ agarose gel. The insert fragments were isolated from gel slices by electroelution into an Elutrap (Schleicher and Schuell) and further purified by Elutip-d column chromatography (Schleicher and Schuell). The DNA was then extracted with phenol/ chloroform $(1: 1)$ and ethanol precipitated. This pool of DNA fragments was labeled either by nick translation using Bio-11dUTP (Langer et al. 1981; Brigati et al. 1983) or by random primer extension with the multiprime DNA labeling system (Amersham) substituting dTTP with $0.5 \mathrm{~m} M$ Bio-11-dUTP. Alternatively, the DNA of the chromosome-specific libraries was biotin-labeled directly (without separation of the vector arms) by nick translation.

Probe size. To facilitate probe penetration and to optimize reannealing hybridization, it is desirable to have labeled DNA fragments smaller than 500 nucleotides, with the majority preferentially of 150 to 250 nucleotides in length. DNAse concentrations were empirically established in nick-translation reactions to yield fragments in the desired size range and this was verified by agarose gel electrophoresis. Random primer extensions were also carried out under conditions which yielded a comparable DNA size distribution.
Competitor DNA. Human genomic DNA (from placenta or white blood cells) prepared as described (Davis et al. 1986) as well as salmon testis genomic DNA (Sigma) were digested with DNAse to obtain fragments with the same size distribution as the probe DNA, then extracted with phenol/chloroform and ethanol precipitated. These competitor DNAs were used in varying ratios with probe sequences, as detailed in the Results.

\section{Preannealing and hybridization}

Under standard conditions from $5 \mu \mathrm{g} / \mathrm{ml}$ to $30 \mu \mathrm{g} / \mathrm{ml}$ of biotinlabeled DNA, representing library insert fragments, and varying amounts of competitor DNAs were combined, ethanolprecipitated and resuspended in formamide. The probe concentration was adjusted to reflect the relative DNA content of each chromosome target. For example, chromosome 1 contains approximately 5.3 times as much DNA as chromosome 21 (Mendelsohn et al. 1973); thus the probe concentrations used were $30 \mu \mathrm{g} / \mathrm{ml}$ and $5 \mu \mathrm{g} / \mathrm{ml}$, respectively. When total library DNA was used as the probe mixture instead of purified DNA inserts, 10 times as much labeled DNA was added to compensate for the large amount of vector sequences. In the case of the X-chromosome library, LA0XNL01, only twice as much labeled library DNA was used since the human DNA inserts constitute almost half of the total DNA. For comparative purposes, the concentration of human competitor DNA in the hybridization mixture was varied from 0 to $1.0 \mathrm{mg} / \mathrm{ml}$ and salmon testis DNA was added as required to result in a final DNA concentration of $1.0 \mathrm{mg} / \mathrm{ml}$ in $50 \%$ formamide, $1 \times \mathrm{SSC}$ ( $0.15 M$ sodium chloride, $0.015 M$ sodium citrate, $\mathrm{pH} 7.0$ ) and $10 \%$ dextran sulfate. These solutions were heated at $75^{\circ} \mathrm{C}$ for 5 min to denature the DNA and then incubated at $37^{\circ} \mathrm{C}$ for various times to promote partial reannealing. The preannealing step was done in an Eppendorf tube just prior to applying the hybridization mixture to the specimen. Nuclei and chromosome spreads on glass slides were incubated in $70 \%$ formamide, $2 \times \mathrm{SSC}$ at $70^{\circ} \mathrm{C}$ for $2 \mathrm{~min}$ to denature chromosomal DNA and then dehydrated in a series of ice-cold ethanol $(70 \%, 90 \%$ and $100 \%$, each for $3 \mathrm{~min})$. After application of the preannealed probe mixture $\left(2.5 \mu 1 / \mathrm{cm}^{2}\right)$ to slides prewarmed to $42^{\circ} \mathrm{C}$, a coverslip was added and sealed with rubber cement. The samples were then immediately incubated at $37^{\circ} \mathrm{C}$ in a moist chamber for $10-20 \mathrm{~h}$.

In those cases where paraformaldehyde fixation was used to more optimally preserve the 3-D structure of the specimen (Manuelidis 1985b), the slides were equilibrated in $50 \%$ formamide, $1 \times \operatorname{SSC}(2 \times 15 \mathrm{~min})$, excess fluid was removed without permitting the sample to dry, the probe mixture was added $\left(5 \mu \mathrm{l} / \mathrm{cm}^{2}\right)$, and a coverslip mounted and sealed with rubber cement. Denaturation of both probe and cellular DNA was done at $75^{\circ} \mathrm{C}$ for $5 \mathrm{~min}$ before hybridization was allowed to proceed overnight at $37^{\circ} \mathrm{C}$.

\section{Detection}

After hybridization, the slides were washed in $50 \%$ formamide, $2 \times \mathrm{SSC}\left(3 \times 5 \mathrm{~min}, 42^{\circ} \mathrm{C}\right)$ followed by washes in $0.1 \times \mathrm{SSC}$ $\left(3 \times 5 \mathrm{~min}, 60^{\circ} \mathrm{C}\right)$. Thereafter the slides were incubated with $3 \%$ bovine serum albumin (BSA), $4 \times \mathrm{SSC}$ for ca. $30 \mathrm{~min}$ at $37^{\circ} \mathrm{C}$. Detection of the biotinylated probe was achieved using either fluorescein-labeled avidin or avidin-alkaline phosphatase complexes. All detection reagents were made up in $4 \times$ SSC, $0.1 \%$ Tween $20,1 \%$ BSA and all washes were car- 
ried out in $4 \times \mathrm{SSC}, 0.1 \%$ Tween $20\left(3 \times 3 \mathrm{~min}, 42^{\circ} \mathrm{C}\right)$. For fluorochrome detection, slides were incubated with $5 \mu \mathrm{g} / \mathrm{ml}$ fluorescein isothiocyanate (FITC)-conjugated avidin DCS (Vector Laboratories) at $37^{\circ} \mathrm{C}$ for $30 \mathrm{~min}$ followed by washes. In rare cases the FITC signal was amplified by incubation with $5 \mu \mathrm{g} / \mathrm{ml}$ biotin-conjugated goat anti-avidin $\mathrm{D}$ antibodies (Vector Laboratories) at $37^{\circ} \mathrm{C}$ for $30 \mathrm{~min}$, followed by washing, a second incubation with $5 \mu \mathrm{g} / \mathrm{ml}$ FITC-conjugated avidin $\left(37^{\circ} \mathrm{C}, 30 \mathrm{~min}\right)$ and a final wash (Pinkel et al. 1986a). For detection by enzyme activity, samples were incubated with $2.5 \mu \mathrm{g} / \mathrm{ml}$ streptavidin, washed, incubated with $2 \mu \mathrm{g} / \mathrm{ml}$ biotinconjugated alkaline phosphatase (Vector Laboratories), washed again and pre-equilibrated in AP-buffer $9.5(100 \mathrm{mM}$ Tris- $\mathrm{HCl}, \mathrm{pH} 9.5,100 \mathrm{mM} \mathrm{NaCl}, 50 \mathrm{mM} \mathrm{MgCl}_{2}$ ) for $2 \times 5 \mathrm{~min}$ at room temperature. The enzyme reaction was carried out in AP buffer 9.5 containing $330 \mu \mathrm{g} / \mathrm{ml}$ of nitroblue tetrazolium (NBT) and $165 \mu \mathrm{g} / \mathrm{ml}$ 5-bromo-4-chloro-3-indolyl phosphate (BCIP) at $37^{\circ} \mathrm{C}$ for $0.5-1 \mathrm{~h}$ and stopped by incubation in $2 \times$ SSC. All preparations were counterstained with $200 \mathrm{ng} / \mathrm{ml}$ 4,6-diamidino-2-phenylindole-dihydrochloride (DAPI), $2 \times$ $\mathrm{SSC}$ for $5 \mathrm{~min}$ at room temperature and mounted in $20 \mathrm{mM}$ Tris- $\mathrm{HCl}, \mathrm{pH} 8.0,90 \%$ glycerol containing $2.3 \%$ of the DAPCO antifade, 1,4 diazabicyclo-(2.2.2)octane (Johnson et al. 1982).

\section{Microscopy}

Preparations were visualized on a Nikon inverted microscope equipped for DAPI and FITC epifluorescence optics as well as for conventional bright field microscopy (visualization of enzyme-mediated color precipitates). Photographs were taken with Kodak Ektachrome 400 (color) or Ilford XP1 400 (black and white) films.

A Nikon Optiphot microscope mounted to a laser scanning confocal imaging system (Bio-Rad Lasersharp MRC-500; White et al. 1987) was used for computer-assisted optical sectioning and three-dimensional reconstruction of fluorescent labeled chromosome domains in nuclei. Stereo pictures of the three-dimensional reconstructed nuclei were taken directly from the video screen or printed on dry silver film (Imaging Systems Division, 3M Company).

\section{Densitometry}

A graphics workstation (VAX station II/GPX, Digital Equipment Corporation) with a frame grabber (ITEX FG-101, Imaging Technology) and a Dage-MTI-65 video camera with a Zeiss S-Planar $60 \mathrm{~mm}$ lens were used as previously described (Manuelidis and Borden 1988). Images were digitized directly from the negatives and stored on disk. Background was removed and polygonal regions around each chromosome were defined. Threshold density levels were used to outline chromosome regions within the defined polygonal areas. Mean density levels within these outlined chromosome regions, $\mathrm{R}$, were determined by the total signal $\int I(x, y) \mathrm{dR} /$ area $\mathrm{R}$, where $\int I(x, y)$ is the pixel intensity $(0-255)$ at each point within the region $\mathrm{R}$. The threshold background intensity was subtracted from the mean regional density both for labeled chromosome 7 and for background chromosomes. The signal to noise ratio was calculated as mean chromosome 7 signal/ mean background chromosome signal.

\section{Results}

Figure $1 \mathrm{~A}$ shows chromosome 7 library inserts labeled with biotin and hybridized to metaphase spreads from normal human lymphocytes without human competitor DNA. Prominent labeling of the two no. 7 chromosomes is observed; additionally, a distinct band-like pattern of hybridization is seen on most of the other chromosomes, and two E-group chromosomes are especially brightly stained. This general chromosomal banding pattern resembles R-banding, and suggests that a significant portion of the background cross-hybridization signal originates from $A l u$ repetitive sequences. Previous studies (Manuelidis and Ward 1984) have shown that Alu sequences delineate an R-banding pattern, while Giemsa positive-banding profiles are highlighted by $K p n I$ interspersed repeats. A series of pilot studies were therefore undertaken to establish experimental parameters to eliminate the hybridization signal from such repetitive elements.

The kinetics of nucleic acid reassociation in solution are dependent on the total concentration of nucleic acid $(\mathrm{Co}$, in moles of nucleotides per liter) and the time of renaturation ( $t$, in seconds). When reassociation conditions are standardized for temperature (taking into account the formamide concentration), cation concentration and buffer system, the reassociation kinetics are comparable with respect to Cot values. Under defined conditions, the fast reassociating fraction of mammalian genomes containing the highly repetitive DNA is completely reannealed at Cot values between $1 \times 10^{-1}$ and $5 \times 10^{-1}$ whereas the intermediate fraction containing the middle repetitive DNA is completely renatured at a Cot value of $1 \times 10^{2}$ (Britten and Kohne 1968). Thus at a human DNA concentration of $1.0 \mathrm{mg} / \mathrm{ml}$ (corresponding to $3 \times 10^{-3}$ moles of nucleotide per liter), the fast fraction would be renatured in approximately $10 \mathrm{~s}$, whereas the middle repetitive DNA would need more than $9 \mathrm{~h}$ to reach complete reannealing. Since the fast fraction of reassociating DNA contains most or all of the ubiquitous repetitive DNA causing cross-hybridization signals, we decided to use a total DNA concentration of $1.0 \mathrm{mg} / \mathrm{ml}$ and allow partial reannealing of the probe mixture prior to application to specimens. The optimal renaturation time was determined empirically (see below). This was important, since our in situ hybridization conditions deviate from the standard conditions under which reassociation kinetics are determined (e.g. hybridization in $50 \%$ formamide at $37^{\circ} \mathrm{C}$ corresponds to $0 \%$ formamide at about $70^{\circ} \mathrm{C}$; dextran sulfate also increases the reassociation time significantly). Furthermore, it was unclear to what degree the middle repetitive DNA contributed to the non-specific signal and therefore should also be prevented from hybridization by the preannealing procedure.

The stringency for the reannealing and in situ hybridization experiments was determined in $50 \%$ formamide at $37^{\circ} \mathrm{C}$ (adapted from standard in situ hybridization protocols) and $1 \times$ SSC [this cation concentration of $0.165 M$ comes close to the concentration used in the kinetics study of Britten and Kohne (1968)]. Competitor human DNA was added in the reassociation procedure to obtain the desired final high DNA concentration and to maintain a high level of repetition of the DNA sequences that should preanneal. While total human genomic DNA represents all the highly repetitive DNA to be removed by preannealing it also contains sequences of the target chromosome, thus the addition of excessive amounts of human DNA would be expected to diminish the chromosomespecific signal. Therefore, we determined first the optimal 

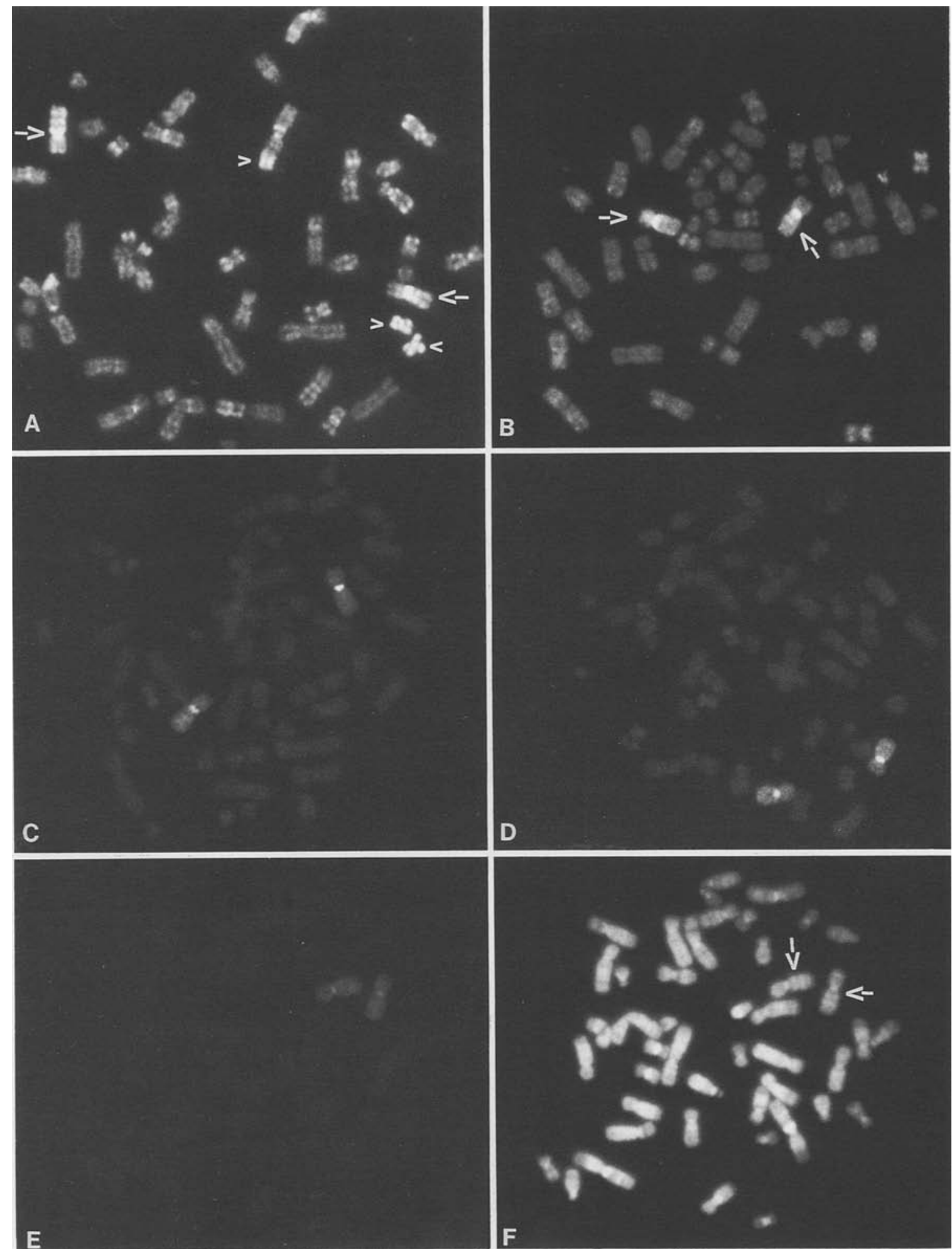

Fig. 1A-F. Suppression of signals from cross-reacting sequences within a chromosome 7-derived DNA library by different concentrations of human competitor DNA. Biotin-labeled chromosome 7 DNA inserts $(20 \mu \mathrm{g} / \mathrm{ml})$ were prehybridized for 20 min with human genomic DNA prior to hybridization with metaphase chromosome spreads and detection with FITC-labeled avidin. Human DNA concentrations were: $\mathbf{A} 0 \mu \mathrm{g} / \mathrm{ml}$, B $50 \mu \mathrm{g} / \mathrm{ml}, \mathbf{C} 100 \mu \mathrm{g} / \mathrm{ml}$, D $200 \mu \mathrm{g} / \mathrm{ml}, \mathbf{E} 1000 \mu \mathrm{g} / \mathrm{ml}$, F same metaphase spread as in E post-stained with DAPI. Genomic salmon DNA was added to each sample to adjust the final DNA concentration to $1.0 \mathrm{mg} / \mathrm{ml}$ (see the text for details). The arrows mark the target chromosome 7 and the arrowheads mark additional strong signals on non-7 chromosomes. All negatives printed were exposed and developed under identical photographic conditions 
concentration of total human DNA to use as the competitor. To keep the total DNA concentration constant at $1.0 \mathrm{mg} / \mathrm{ml}$, genomic salmon DNA was added as needed. Salmon DNA shares certain repetitive DNA elements, such as poly $\mathrm{dCdA}$ (Hamada et al. 1982) in common with human DNA, but lacks others, most notably the $A l u-$ and $K p n I$ repeats. This results in a lower frequency of the latter sequences with increasing amounts of salmon DNA in the reassociation reaction.

Figure 1 shows typical experimental results obtained when $20 \mu \mathrm{g} / \mathrm{ml}$ of the chromosome 7 probe set was denatured together with $50 \mu \mathrm{g} / \mathrm{ml}$ (B), $100 \mu \mathrm{g} / \mathrm{ml}$ (C), $200 \mu \mathrm{g} / \mathrm{ml}$ (D) or $1000 \mu \mathrm{g} / \mathrm{ml}$ (E) of DNAse-digested human genomic DNA which was preannealed for $20 \mathrm{~min}$. Hybridization and detection using avidin-FITC were carried out as described in Materials and methods. From each preparation ten black and white pictures were taken under standardized photographic conditions for densitometric studies (see below). In the absence of human genomic competitor (A) the signal showed little chromosomal specificity. However, with 50 and $100 \mu \mathrm{g} / \mathrm{ml}$ of human competitor DNA an increase of label specificity is readily apparent (Fig. 1B, C). Specific staining of chromosome 7 was achieved with a peak of signal intensity using 100 and $200 \mu \mathrm{g} / \mathrm{ml}$ of human competitor DNA (Fig. 1C, D). Higher concentrations of human DNA caused an apparent decrease of signal intensity, especially at $1000 \mu \mathrm{g} / \mathrm{ml}$ human DNA (Fig. 1E). However, the signal obtained under these latter conditions is still reasonably bright to the observer, but requires a different exposure for optimal illustration (not shown).

A computer-assisted method of quantitative densitometry (see Materials and methods) was used to establish the overall level of labeling specificity. The ratio of fluorescence signal from the target chromosomes of interest to the background fluorescence noise emanating from non-target chromosomes was determined from images digitized from multiple photographic negatives of a DNA titration experiment, as illustrated in Fig. 1. The signal-to-noise ratio obtained with each concentration of human competitor DNA is given in Table 1. Optimal reannealing conditions for suppression of nonspecific signal (using $20 \mu \mathrm{g} / \mathrm{ml}$ of chromosome 7 probe and $100-200 \mu \mathrm{g} /$ $\mathrm{ml}$ human genomic (DNA), gave a signal-to-noise ratio of ca. $8: 1$. Additional attempts to improve the signal to noise ratio by increasing hybridization stringencies (e.g. $60 \%$ formamide or $0.2 \times \mathrm{SSC}$ ) gave no apparent improvement and led to an overall decrease in signal intensity.

Since about $100-200 \mu \mathrm{g} / \mathrm{ml}$ of human competitor DNA was shown to give the optimal specificity, $200 \mu \mathrm{g} / \mathrm{ml}$ was used for another analysis of signal specificity with respect to the renaturation time (see above). After $0,2,5,10,20,40$ and $60 \mathrm{~min}$ of preannealing, aliquots were taken and used for in situ hybridization experiments as before. As indicated in Fig. 2, specific labeling was obtained for all preannealing times. A small improvement of the signal is seen with increasing renaturation times from 0 to $20 \mathrm{~min}$. Longer renaturation times up to $60 \mathrm{~min}$ (not shown) gave no significant improvement in signal strength or chromosome specificity. The subjective impression of a signal improvement with $20 \mathrm{~min}$ of preannealing (Fig. 2D) could not be confirmed by a densitometric analysis, carried out as described above, since no significant differences in the signal-to-noise ratio of the different preannealing times were observed (data not shown). We chose $10-20 \mathrm{~min}$ as the standard renaturation time in all subsequent experiments. Since a signal is clearly visible at renaturation time 0 , the few seconds necessary for transferring the probe mixture to the
Table 1. Densitometric analysis of the suppression of cross hybridization signals by various concentrations of human competitor DNA. Chromosome 7 DNA inserts were labeled with biotin and hybridized in a competitor DNA titration experiment, as illustrated in Fig. 1. $n$, Number of chromosomes from which the mean was determined

\begin{tabular}{|c|c|c|c|c|c|}
\hline \multirow{2}{*}{$\begin{array}{l}\text { Human } \\
\text { competitor } \\
\text { DNA conc. } \\
(\mu \mathrm{g} / \mathrm{ml})\end{array}$} & \multicolumn{2}{|l|}{ Signal } & \multicolumn{2}{|l|}{ Noise } & \multirow{2}{*}{$\begin{array}{l}\text { Signal-to-noise } \\
\text { ratio } \\
\text { Confidence } \\
\text { interval }^{c}(99 \%)\end{array}$} \\
\hline & Pixel $^{\mathrm{a}}$ & $n$ & Pixel $^{\text {b }}$ & $n$ & \\
\hline 0 & 71.48 & 8 & 54.66 & 26 & $1.31 \pm 0.04$ \\
\hline 50 & 74.50 & 8 & 37.43 & 28 & $1.99 \pm 0.07$ \\
\hline 100 & 162.64 & 8 & 20.06 & 23 & $8.11 \pm 0.35$ \\
\hline 200 & 147.35 & 8 & 20.53 & 26 & $7.18 \pm 0.37$ \\
\hline 500 & 89.78 & 8 & 18.63 & 21 & $4.82 \pm 0.28$ \\
\hline 1000 & 94.37 & 8 & 30.51 & 17 & $3.09 \pm 0.12$ \\
\hline
\end{tabular}

${ }^{a}$ Mean value of pixel intensity of target chromosome

b Mean value of pixel intensity of non-target chromosomes (from the same metaphase spreads)

c The confidence interval was calculated using Fieller's theorem (Finney 1971)

microscope slide appear to be sufficient to effectively preanneal many of the sequences that cause nonspecific labeling by cross-hybridization. Furthermore, the large excess of single-stranded competitor DNA may efficiently compete with the biotinylated probe sequences for ubiquitous chromosomal target sites during the hybridization reactions. These results demonstrate that the majority of highly repetitive DNA sequences can be sufficiently suppressed to achieve chromosome-specific labeling by in situ hybridization.

In certain cases the signal distribution over the entire chromosome shows some variability from experiment to experiment. When the overall signal is decreased some chromosomal subregions show a brighter staining; these signal hotspots generally constitute chromosomal sites that contain known chromosome-specific repetitive sequences. In the experiments shown in Figs. 1 and 2, predominant staining of the centromeric region of chromosome 7 is seen, which corresponds to the chromosome-specific signal of an alphoid repetitive DNA (Waye et al. 1987; see also Cremer et al. 1988b). Apparently, the abundance of these repeated sequences is sufficiently low to prevent their suppression under the conditions used here. The unequal signal distribution can be overcome by amplifying the overall signal using an antibody sandwich technique as described in Materials and methods. Furthermore, when labeling chromosome 1 , we frequently saw a predominant staining of the region 1q12 (see Cremer et al. 1988b) that corresponds to the chromosomal site of satellite III DNA (Cooke and Hindley 1979; Gosden et al. 1981). An example of the balanced signal distribution seen after such an amplification step is shown in Fig. 3A.

We tested several commercially available DNA libraries; each representing a single human chromosome, for their ability to specifically label that chromosome under the standardized reannealing conditions described above and with the probe concentrations adjusted for chromosome size (see Materials and methods). Some examples, for chromosomes 1, 4, 7, 13, 18 and 20, as shown in Fig. 3, clearly demonstrate that specific labeling can be achieved with most chromosome libraries. Table 2 lists the libraries tested with their relative scores of labeling specificity. All scores are positive because the chromosome of interest was always decorated. The highest 


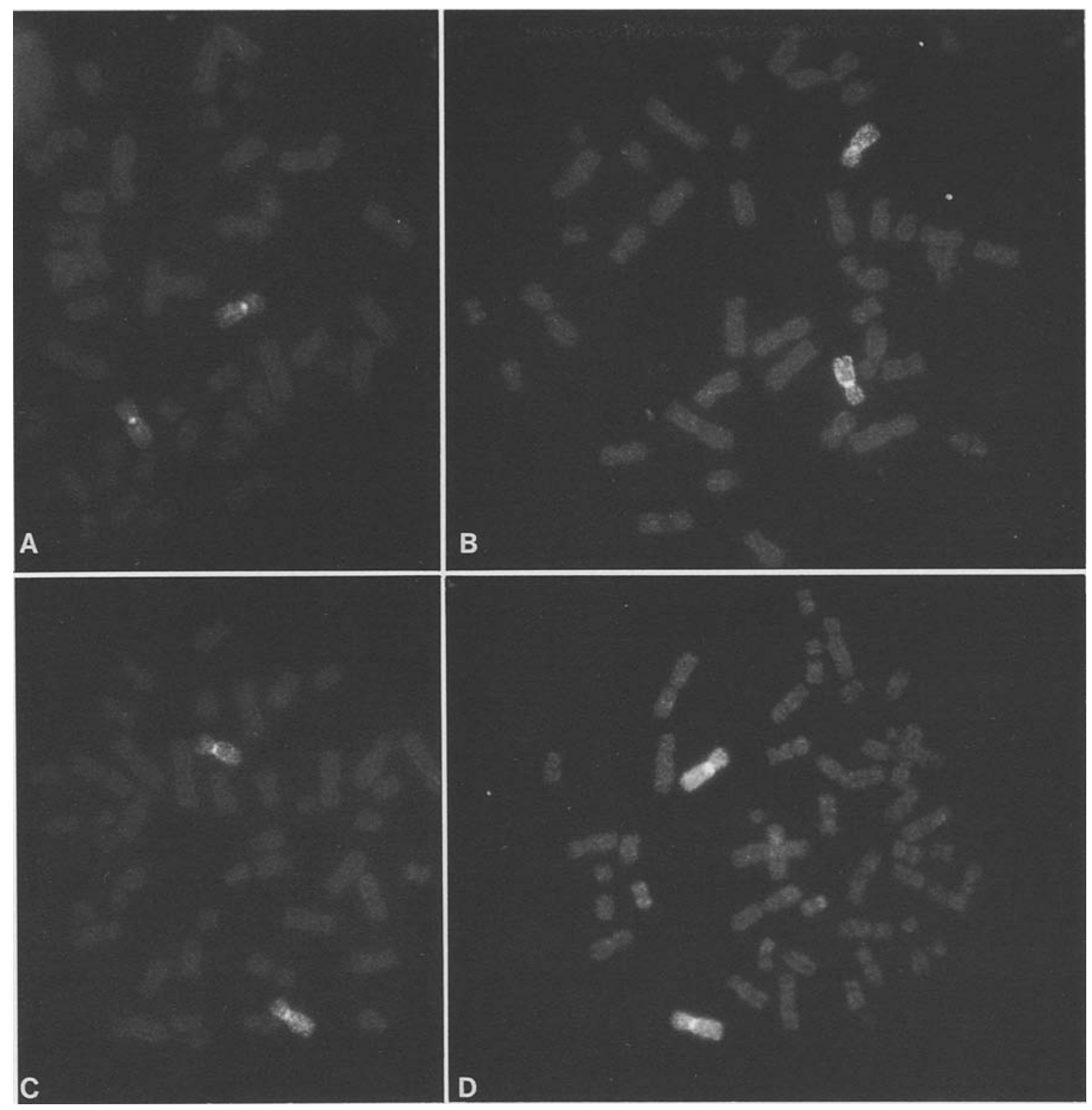

Fig. 2A-D. Effect of preannealing time on the specificity and strength of the hybridization signal. A sample of $20 \mu \mathrm{g} / \mathrm{ml}$ biotin-labeled chromosome 7 DNA inserts was preannealed with $200 \mu \mathrm{g} / \mathrm{ml}$ human competitor DNA for various times: A $0 \mathrm{~min}$, B $2 \mathrm{~min}$, C $5 \mathrm{~min}$, D $20 \mathrm{~min}$, before hybridization to metaphase spreads followed by detection with FITC-conjugated avidin

score $(4+)$ is used when no significant cross-hybridization to other chromosomes was observed and the scores decrease $(3+$ to $1+$ ) with an increasing amount of cross-hybridizing sequences.

All attempts to reduce the additional signals on other chromosomes by varying the experimental conditions failed except in experiments with chromosome 22 ; in this case higher concentrations of human competitor DNA $(700 \mu \mathrm{g} / \mathrm{ml})$ resulted in a significant improvement of signal specificity. The library exhibiting the lowest chromosome specificity was the chromosome 13 library (Fig. 3E). Multiple minor binding sites on other chromosomes, as well as an exceptionally bright staining of $\mathrm{Yq} 12$ were observed; the signal on the $\mathrm{Y}$ chromosome was visible using either female or male human DNA as the competitor. None of the experimental parameters tested improved on the overall specificity of this library.

Remarkably, a weak signal or even absence of signal can be observed at the centromeric region of some chromosomes (see chromosomes 4 and 18, Fig. 3C, D). In contrast to chromosomes 1 and 7 which contain chromosome-specific repetitive elements, the centromere regions of chromosomes 4 and 18 apparently contain repetitive sequences, most likely alphoid satellite DNAs, which are very abundant and thus are suppressed by the reannealing technique. However, these chromosomal regions are very small and the effect can only be observed when the corresponding chromosomes are fairly elongated.

We also used biotinylated total library DNA (containing the phage vector sequences) as probes in concentrations adjusted to the amount of human DNA inserts (see Materials and methods). One example is shown in Fig. $3 \mathrm{~F}$ with the chromosome 20 library. Although good staining of the chromosome of interest generally was achieved, significant nonspecific background on the entire slide was a common problem. Similar results were obtained with plasmid libraries containing human DNA subcloned from the lambda phage 


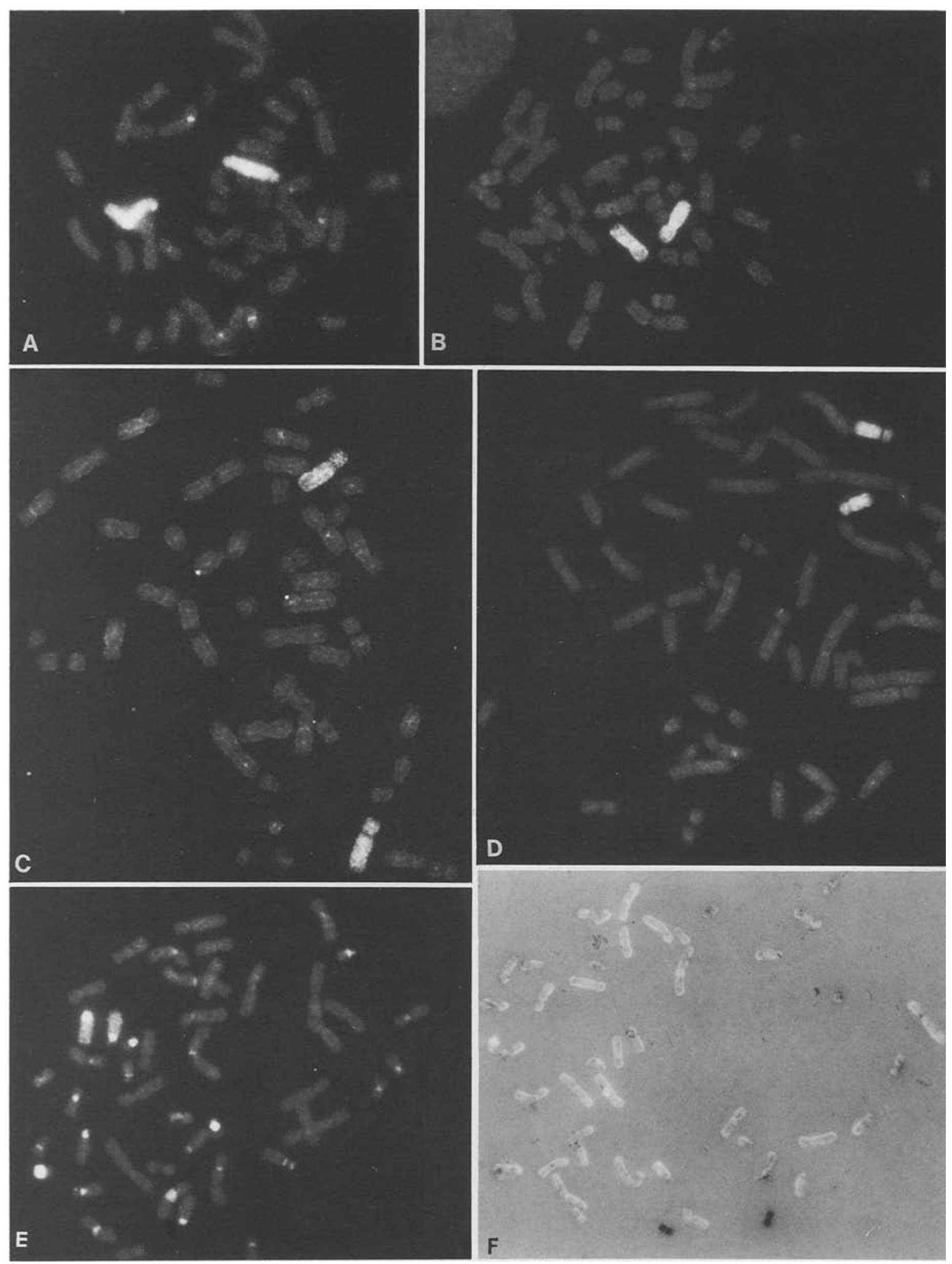

Fig.3A-F. Decoration of A chromosome 1, B chromosome 7, C chromosome 4, $\mathbf{D}$ chromosome 18, $\mathbf{E}$ chromosome 13 and $\mathbf{F}$ chromosome 20 in normal human lymphocytes. Only the chromosome 13 insert DNA pool shows significant cross-hybridization to other chromosomes after the prehybridization supression step. The detection of chromosome 20 (F) was done with the entire chromosome library (including $\lambda$ phage arms) and detected with avidin-alkaline phosphatase using NBT-BCIP as the enzyme substrate mixture. The signal of chromosome 1 (A) was amplified by the sandwich technique of Pinkel et al. (1986a) 
libraries (Chieh-ju Tang, P. Lichter, D. C. Ward, unpublished data). In contrast, there was no background problem with the total chromosome library LA0XNL01, which contains a significantly smaller proportion of vector sequences in the probe

Table 2. Relative quality of specific chromosome labeling in situ using preannealed biotinylated library DNA inserts

\begin{tabular}{rll}
\hline Chromosome & $\begin{array}{l}\text { Library used } \\
\text { (ATCC designation) }\end{array}$ & $\begin{array}{l}\text { Relative specificity } \\
\text { of in situ hybridization } \\
\text { signal }^{\mathrm{a}}\end{array}$ \\
\hline 1 & LA01NS01 & $3+$ \\
4 & LL04NS01 & $4+$ \\
7 & LA07NS01 & $4+$ \\
8 & LL08NS02 & $4+$ \\
13 & LA13NS03 & $1+$ \\
14 & LL14NS01 & $2+$ \\
18 & LL18NS01 & $4+$ \\
20 & LL20NS01 & $4+$ \\
21 & LL21NS02 & $3+$ \\
22 & LA22NS03 & $3+{ }^{\mathrm{b}}$ \\
$\mathrm{X}$ & LA0XNL01 & $4+$ \\
\hline
\end{tabular}

${ }^{a}$ See the text for score definition

b Under standard preannealing conditions the chromosome 22 library gave a score of +1 ; a value of +3 was achieved only with a human competitor DNA concentration of $\geq 700 \mu \mathrm{g} / \mathrm{ml}$ (total DNA concentration $1.0 \mathrm{mg} / \mathrm{ml}$ ) mixture since the size of the human DNA inserts is much larger.

The suppression of repetitive sequences by this reannealing technique also permits the use of flow-sorted chromosome libraries to detect chromosomal domains within interphase nuclei. Typical examples of results obtained after hybridization of chromosome 1, chromosome 7 and chromosome 18 probe sets to normal human lymphocytes after acetic acidmethanol fixation are shown in Fig. 4. Discrete focal domains of hybridization signal are seen with all libraries that had scores of $2+$ or more (see Table 2 ). Most nuclei ( $n \geq 100$ per estimate) exhibited two domains (60\%-70\%); however, a significant number showed only a single domain $(20 \%-30 \%)$ or no hybridization signal at all $(5 \%-10 \%)$. Accordingly, ca. $95 \%$ of male nuclei exhibited one and ca. $5 \%$ showed no hy. bridization signal when the $\mathrm{X}$ chromosome library DNA was used as probe. Notably, no nuclei with three domains were found with any of the chromosomal probe sets tested. In contrast, all metaphase spreads showed the decoration of both chromosome homologs without exception. This interphase variability may reflect, in part, the close juxtaposition of two individual domains in some cells, or the inability to resolve domains that actually occupy different areas within the nuclear volume but are unresolved when examined by two-dimensional imaging methods (see Fig. 4D; for discussion see also Cremer et al. 1988a). The small number of nuclei exhibiting no hybridization signal may be a reflection of suboptimal hy-
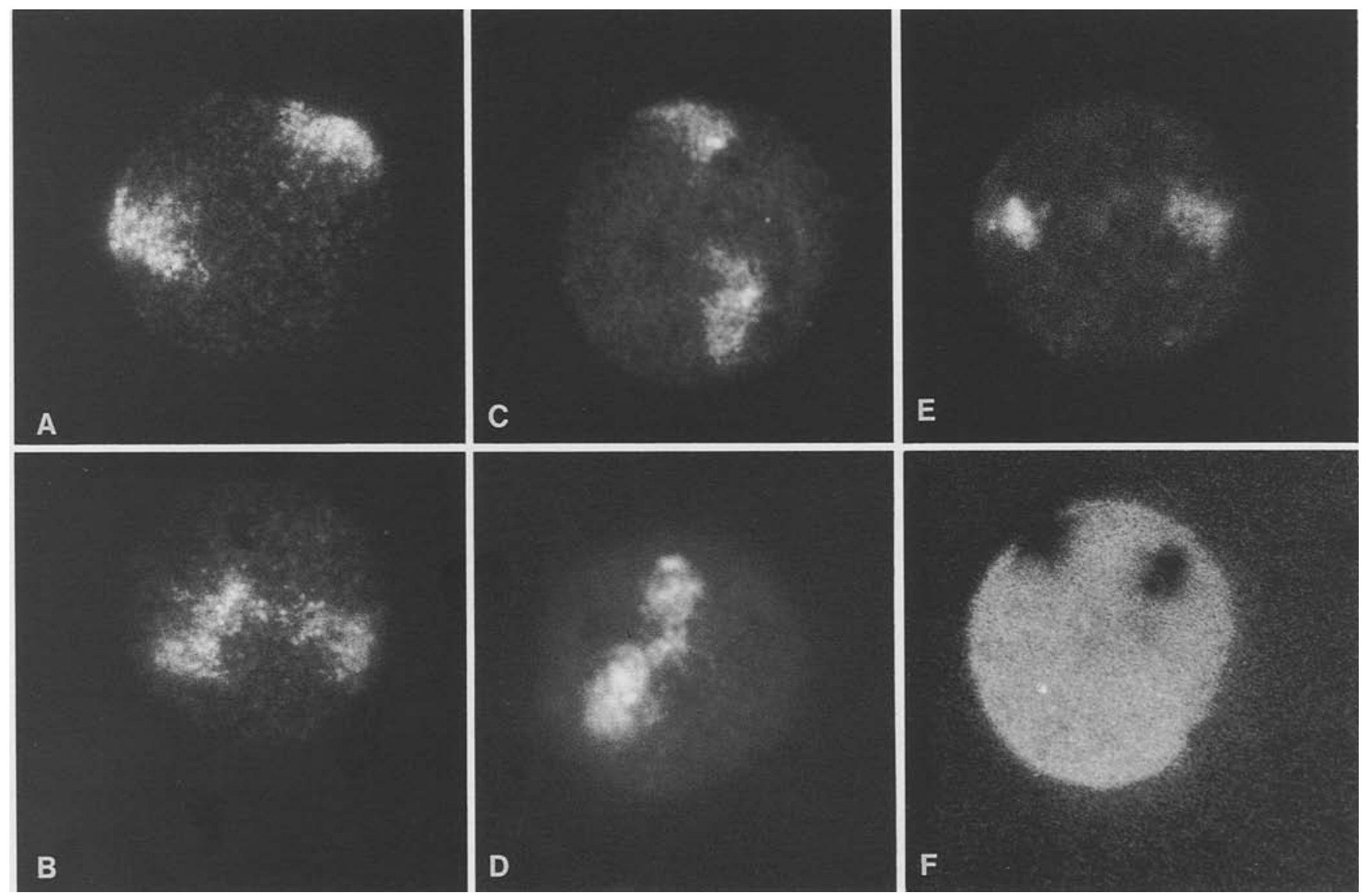

Fig. 4A-F. Chromosome domains in human lymphocyte nuclei delineated by preannealed chromosome library DNA inserts. Hybridization to acetic acid-methanol fixed nuclei was detected by FITC-conjugated avidin (A-E) or alkaline phosphatase-conjugated avidin (F). Domains are shown for chromosome $1(\mathbf{A}, \mathbf{B})$, chromosome $7(\mathbf{C}, \mathbf{D})$ and chromosome $18(\mathbf{E}, \mathbf{F})$. A predominant staining of the centromere region is seen within the chromosome 7 domains, reflecting preferential hybridization of the chromosome 7-specific alphoid DNA repeat; a similar signal distribution on metaphase chromosomes was also observed in this particular experiment 


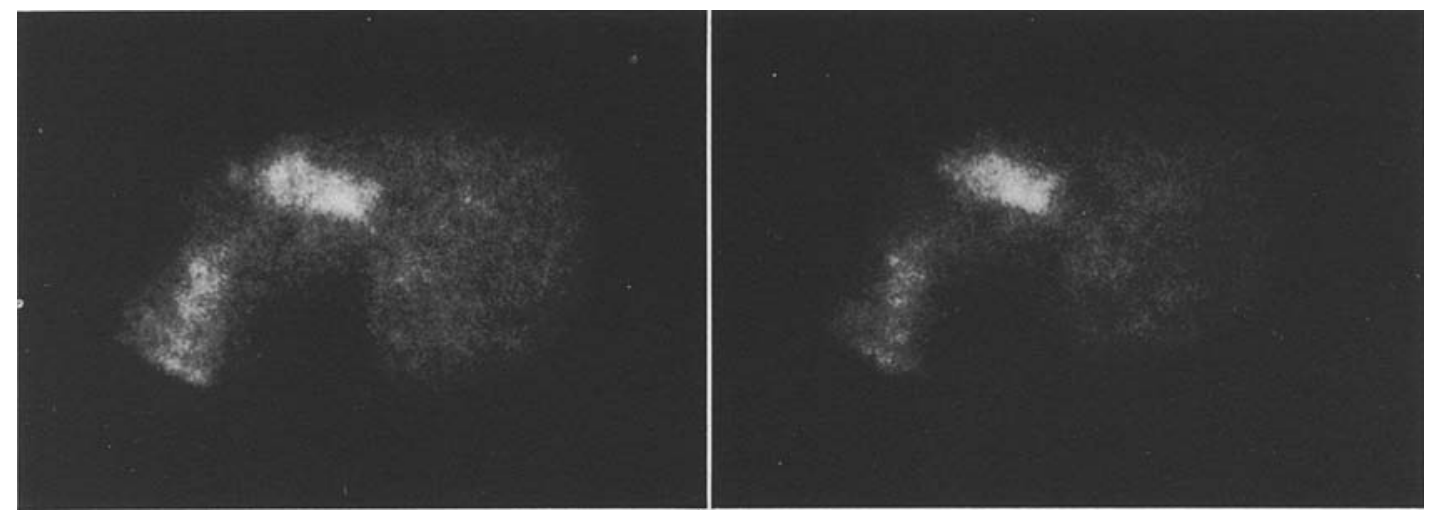

Fig.5. Stereo picture of a human foreskin fibroblast nucleus highlighting chromosome 7-specific DNA domains. Hybridization to paraformaldehyde-fixed fibroblasts and detection with FTTC-labeled avidin was carried out as described in Materials and methods. Using a laser-scanning confocal microscope, 14 continuous optical sections were taken at $0.5-\mu \mathrm{m}$ intervals and used for $3-\mathrm{D}$ reconstruction. Whereas the lower domain extends in the plain of the print, the upper domain is oriented more upright towards the viewer's eye. A helical substructure of the domains is visible (see the text for discussion). The nucleolus is excluded from the nuclear background staining (here partially framed by the two labeled domains)

bridization conditions. It is of interest to note that the size of the intranuclear domains correlates reasonably well with the relative size of the cognate metaphase chromosome. These observations provide a definitive proof that the DNA of individual chromosomes exhibits a clear territorial organization in the interphase nucleus of a normal human cell.

Acetic acid-methanol fixed nuclear spreads, such as those shown in Fig. 4, clearly retain the territorial organization for each of the chromosomes examined; however, the nuclear structure is not optimally preserved. We have initiated studies with specimens that possess better preservation of 3-D structure using paraformaldehyde fixed human diploid fibroblasts and a laser-scanning confocal fluorescence microscope assembly for 3-D image reconstruction. The cells were fixed and permeabilized as described by Manuelidis (1985b) and hybridized with chromosome library probes as outlined in Materials and methods. The probe-competitor DNA mixture was applied directly to the slide and denatured at the same time as the cellular DNA. Figure 5 shows a stereo pair illustrating the spatial organization of the two chromosome 7 domains within a cell nucleus reconstructed after optical sectioning. Besides the arrangement of the chromosome domains in the nucleus, this figure also shows the frequently observed helical structure of labeled chromatin within chromosome domains. The degree to which this helicity reflects true domain substructure or an artifact reflecting preparation and fixation procedures is currently being investigated. Nevertheless, this preliminary observations establishes the feasibility of using chromosomespecific probes to analyze the topography of chromosomal domains in the interphase cells.

\section{Discussion}

In this study we present a method for the efficient and specific labeling of entire individual human chromosomes by in situ hybridization with DNA probes originating from flow-sorted chromosome libraries. Suppression of the signal from the fast reassociating fraction of human genomic DNA was shown, in general, to be sufficient for labeling specificity. Thus the chromosome-specific signal is apparently generated by a combination of middle repetitive, low copy number and unique sequences. A highly specific decoration of the chromosome of interest was achieved with most of the DNA libraries tested, the best of which were the libraries for chromosomes $4,7,8$, 18,20 and $\mathrm{X}$. Total recombinant library DNA containing vector sequences can be used as well as purified DNA inserts, although with somewhat higher background noise, thus circumventing the time and labor needed to isolate and purify pools of insert DNA for use as probes. These commercially available DNA libraries are therefore perfectly adequate for chromosomal analysis of the type reported in this and the following paper (Cremer et al. 1988b). Similar results have been observed by J. Gray, D. Pinkel and associates (personal communication) using chromosome 4 and chromosome 21 DNA probe sets. We propose to refer to this method as "chromosomal in situ suppression (CISS)" hybridization.

CISS hybridization may also provide a relatively simple screening method to assess the chromosomal specificity of such libraries and to monitor for gross contamination in flowsorted chromosome fractions. It cannot be determined from our present data whether the observed nonspecific signals are caused by sequences derived from other chromosomes or chromosomal fragments that contaminated the sorted human chromosome fractions, or if they are caused by naturally occurring sequence similarities. However, at least some of the cross-hybridization signals on other chromosomes are apparently produced by sequences that are located on several human chromosomes. For example, a sequence of the satellite III DNA that hybridizes predominantly to chromosome 1 (1q12) also shares homology with several other polymorphic centromeric regions that are present in chromosome 9 and 16 (Gosden et al. 1981). This correlates well with the minor binding sites observed in experiments labeling chromosome 1 (see Fig. 3A). Similarly, part of the cross-hybridization signals of chromosome 22 (not shown) correlates with the hybridization pattern of an $\alpha$-satellite DNA sequence (McDermid et al. 1986), and the cross-hybridization with probes of chromosomes $13,14,21$ and 22 correlates to some extent with the nucleolar organizer regions in the human genome that are known to contain tandemly repeated DNA sequences. In contrast, the expected decoration of the pseudo-autosomal region on the $\mathrm{Y}$ chromosome using $\mathrm{X}$ chromosome library probes was barely visible. 
The fluorescent signals decorating one pair of chromosomes were easily detected and analyzed in mitotic cells, including those usually not accessible to cytogenetic analyses such as early prophase chromosome coils and metaphase spreads where the chromosomes are not well separated from each other (see Cremer et al. 1988b). In addition, interphase domains of the respective chromosomes were distinctly delineated. This constitutes a definite proof for the territorial organization of chromosomes in normal human interphase cell nuclei and extends previous results obtained with rodenthuman hybrid lines (Schardin et al. 1985; Manuelidis 1985a; Pinkel et al. 1986a). This territorial organization facilitates the detection of numerical and structural chromosome aberrations in interphase nuclei (see Cremer et al. 1988b). Furthermore, these observations open up a new approach to investigate interphase chromosome topography. We have demonstrated here the successful staining of individual chromosomes in nuclei of paraformaldehyde-fixed fibroblast cells and a three-dimensional imaging of these respective domains. This procedure should enable one to address such general questions as exclusive territorial occupation, specific localization and specific orientation of chromosome domains in different cell types. We are currently investigating these topographic features and their dependence on the cell cycle and stage of differentiation.

Two technical points that are critical for detailed topological studies should be noted. First, it will be essential to perform optical sectioning routinely in order to spatially resolve juxtaposed or overlapping chromosome domains. This can be done using Normarski or epifluorescence optics, image digitizers and computer-assisted 3-D image reconstruction software as previously reported (Agard and Sedat 1983; Pinkel et al. 1986b; Manuelidis and Borden 1988). As shown here, one also can apply laser-scanning confocal microscopy in combination with computer-controlled image reconstruction to define 3-D structure. Confocal microscopy offers the singular advantage that the contribution of out-of-focus signal can be markedly reduced (Cremer and Cremer 1978; Brakenhoff et al. 1979), thus significantly reducing the mathematical computation required for 3-D image reconstruction. The second important requirement is the availabiltiy of multiple labeling techniques for probe detection. Simultaneous visualization of several chromosome domains or subdomains within the same nucleus would allow a much more extensive investigation of nuclear topography. For example, the combination of complete chromosome domain probes with specific subregional probes would facilitate the analyses of both domain orientation and intradomain fine structure. These subregions could be decorated using chromosome-specific repetitive DNA probes, directed to centromeric and telomeric regions (Manuelidis 1984; Rappold et al. 1984; Manuelidis and Borden 1988; Emmerich et al. 1988; Trask et al. 1988) or cosmid clones containing human DNA of known chromosomal map coordinates (Landegent et al. 1987). The application of double labeling techniques to visualize simultaneously entire chromosome domains and centromeric subregions have already proven valuable for detecting chromosomal aberrations in tumor cells, both in metaphase and interphase cells, as outlined by Cremer et al. (1988b).

Acknowledgements. We would like to thank Martin Ferguson for his help with experiments using chromosomes 8 and 14 probes and Chiehju Tang for skillful technical assistance. P.L. is the recipient of a train- ing grant and T.C. of a Heisenberg stipendium, both from the Deutsche Forschungsgemeinschaft. The work of L.M. has been supported by NIH grant CA-15044 and of D.C.W. by NIH grants GM-32156 and GM-40115.

\section{References}

Agard DA, Sedat JW (1983) Three-dimensional architecture of a polytene nucleus. Nature 302:676-681

Brakenhoff GJ, Blom P, Barends P (1979) Confocal scanning light microscopy with high aperture immersion lenses. J Microsc $117: 219-232$

Brigati DJ, Myerson D, Leary JJ, Spalholz B, Travis SZ, Fong CKY, Hsiung GD, Ward DC (1983) Detection of viral genomes in cultured cells and paraffin-embedded tissue sections using biotinlabeled hybridization probes. Virology 126:32-50

Britten RJ, Kohne DE (1968) Repeated sequences in DNA. Science $161: 529-540$

Cooke HJ, Hindley J (1979) Cloning of human satellite III DNA: different components are on different chromosomes. Nucleic Acids Res 6:3177-3197

Cremer C, Cremer T (1978) Considerations on a laser-scanningmicroscope with high resolution and depth of field. Microscopica Acta $81: 31-44$

Cremer T, Cremer C, Baumann H, Luedtke EK, Sperling K, Teuber $\mathrm{V}$, Zorn C (1982) Rabl's model of the interphase chromosome arrangement tested in Chinese hamster cells by premature chromosome condensation and laser-UV-microbeam experiments. Hum Genet 60:46-56

Cremer T, Landegent J, Brückner A, Scholl HP, Schardin M, Hager HD, Devilee P, Pearson P, Ploeg M van der (1986) Detection of chromosome aberrations in the human interphase nucleus by visualization of specific target DNAs with radioactive and non-radioactive in situ hybridization techniques: diagnosis of trisomy 18 with probe L1.84. Hum Genet 74:346-352

Cremer T, Tesin D, Hopman AHN, Manuelidis L (1988a) Rapid interphase and metaphase assessment of specific chromosomal changes in neuroectodermal tumor cells by in situ hybridization with chemically modified DNA probes. Exp Cell Res 176:199-220

Cremer T, Lichter P, Borden J, Ward DC, Manuelidis L (1988b) Detection of chromosome aberrations in metaphase and interphase tumor cells by in situ hybridization using chromosome-specific library probes. Hum Genet $80: 235-246$

Davis LG, Dibner MD, Battey JF (1986) Basic methods in molecular biology. Elsevier, New York Amsterdam

Emmerich P, Loos P, Jauch A, Hopman AHN, Wiegant J, Higgins M, White BN, Ploeg M van der, Cremer C, Cremer T (1988) Double in situ hybridization in combination with digitized image analysis: a new approach to study interphase chromosome topography. Exp Cell Res (in press)

Finney DJ (1971) Statistical methods in biological assay, 2nd edn. Hafner Press, New York

Gosden JR, Lawrie SS, Cooke HJ (1981) A cloned repeated DNA sequence in human chromosome heteromorphisms. Cytogenet Cell Genet 29:32-39

Hamada H, Petrino MG, Kakunaga T (1982) A novel repeated element with Z-DNA-forming potential is widely found in evolutionary diverse eukaryotic genomes. Proc Natl Acad Sci USA $79: 6465-6469$

Hens L, Baumann H, Cremer T, Sutter A, Cornelis JJ, Cremer C (1983) Immunocytochemical localization of chromatin regions UV-microirradiated in S-phase or anaphase: evidence for a territorial organization of chromosomes during the cell cycle of Chinese hamster cells. Exp Cell Res 149:257-269

Johnson GD, Davidson RS, McNamee KC, Russell G, Goodwin D, Holborow EJ (1982) Fading of immunofluorescence during microscopy: a study of the phenomenon and its remedy. J Immunol Methods $55: 231-242$

Landegent JE, Jansen in de Wal N, Dirks RW, Baas F, Ploeg M van der (1987) Use of whole cosmid cloned genomic sequences for chromosomal localization by non-radioactive in situ hybridization. Hum Genet 77:366-370 
Langer PR, Waldrop AA, Ward DC (1981) Enzymatic synthesis of biotin-labeled polynucleotides: novel nucleic acid affinity probes. Proc Natl Acad Sci USA 78:6633-6637

Maniatis T, Fritsch EF, Sambrook J (1982) Molecular cloning: a laboratory manual. Cold Spring Harbor Laboratory, Cold Spring Harbor, NJ

Manuelidis L (1984) Different central nervous system cell types display distinct and nonrandom arrangements of satellite DNA sequences. Proc Natl Acad Sci USA 81:3123-3127

Manuelidis L (1985a) Individual interphase chromosome domains revealed by in situ hybridization. Hum Genet 71:288-293

Manuelidis L (1985b) Indications of centromere movement during interphase and differentiation. Ann NY Acad Sci 450:205-221

Manuelidis L, Borden J (1988) Reproducible compartmentalization of individual chromosome domains in human CNS cells revealed by in situ hybridization and three dimensional reconstruction. Chromosoma 96:397-410

Manuelidis L, Ward DC (1984) Chromosomal and nuclear distribution of the HindIII 1.9-kb human DNA repeat segments. Chromosoma 91:28-38

McDermid HE, Duncan AMV, Higgins MJ, Hamerton JL, Rector E, Brasch KR, White BN (1986) Isolation and characterization of an $\alpha$-satellite repeated sequence from human chromosome 22 . Chromosoma 94:228-234

Mendelsohn ML, Mayall BH, Bogart E, Moore DH II, Perry BH (1973) DNA content and DNA-based centromeric index of the 24 human chromosomes. Science 179:1126-1129

Pinkel D, Straume T, Gray JW (1986a) Cytogenetic analysis using quantitative, high sensitivity, fluorescence hybridization. Proc Natl Acad Sci USA 83:2934-2938

Pinkel D, Gray JW, Trask B, Engh G van den, Fuscoe J, Dekken H van (1986b) Cytogenetic analysis by in situ hybridization with fluorescently labeled nucleic acid probes. Cold Spring Harbor Symp Quant Biol 51:151-157
Rappold GA, Cremer T, Hager HD, Davies KE, Müller CR, Yang T (1984) Sex chromosome positions in human interphase nuclei as studied by in situ hybridization with chromosome specific DNA probes. Hum Genet $67: 317-325$

Schardin M, Cremer T, Hager HD, Lang M (1985) Specific staining of human chromosomes in Chinese hamster $\times$ man hybrid cell lines demonstrates interphase chromosome territories. Hum Genet 71 : 281-287

Sealey PG, Whittaker PA, Southern EM (1985) Removal of repeated sequences from hybridization probes. Nucleic Acids Res 13: 1905-1922

Trask B, Engh G van den, Pinkel D, Mullikin J, Waldman F, Dekken H van, Gray J (1988) Fluorescence in situ hybridization to interphase cell nuclei in suspension allows flow cytometric analysis of chromosome content and microscopic analysis of nuclear organization. Hum Genet 78:251-259

Van Dilla MA, Deaven LL, Albright KL, Allen NA, Aubuchon MR, Bartholdi MF, Brown NC, Campbell EW, Carrano AV, Clark LM, Cram LS, Crawford BD, Fuscoe JC, Gray JW, Hildebrand CE, Jackson PJ, Jett JH, Longmire JL, Lozes CR, Luedemann ML, Martin JC, McNinch JS, Meincke LJ, Mendelsohn ML, Meyne J, Moyzis RK, Munk AC, Perlman J, Peters DC, Silva AJ, Trask BJ (1986) Human chromosome-specific DNA libraries: construction and availability. Biotechnology 4:537-552

Waye JS, England SB, Willard HF (1987) Genomic organization of alpha satellite DNA on human chromosome 7: evidence for two distinct alphoid domains on a single chromosome. Mol Cell Biol $7: 349-356$

White JG, Amos WB, Fordham M (1987) An evaluation of confocal versus conventional imaging of biological structures by fluorescence light microscopy. J Cell Biol 105:41-48

Received June 27, 1988 / Revised July 15, 1988 